\title{
Sizing of Hybrid Electric Propulsion System for Retrofitting a Mid- Scale Aircraft Using Non-dominated Sorting Genetic Algorithm
}

\author{
Ye Xie $^{\mathrm{a}, *}$, Al Savvaris ${ }^{\mathrm{a}}$, Antonios Tsourdos ${ }^{\mathrm{a}}$ \\ ${ }^{a}$ School of Aerospace, Transport and Manufacturing, Cranfield University, Bedford, MK43 OAL, United Kingdom
}

\begin{abstract}
The paper presents the sizing of a hybrid electric propulsion system for a prototype aircraft. The main contribution of the paper is to apply multi-objective optimization in the retrofit of a mid-scale aircraft and investigate the fuel economy of the hybrid aircraft for a particular mission cycle. Using the Non-dominated Sorting Genetic Algorithm (NSGA), the fuel consumptions for different flight durations are minimized, which represent the optimal trade-off between fuel consumption and flight duration. With no compromise on endurance and range, the maximum fuel reduction of the retrofitted hybrid aircraft reaches $17.6 \%$, by comparison with the prototype aircraft. The retrofitted aircraft achieves better cruising and climbing performance with the sized hybrid propulsion system. The novelty of the study is the proposal of a new non-dominated sorting algorithm-Benchmark based NonDominated Sort (BNDS) for the NSGA. BNDS can reduce the number of comparisons and the time complexity of the non-dominated sorting process. A constraint handling approach is also integrated into the BNDS/NSGA to address performance and mission requirements.
\end{abstract}

Keywords: Mid-scale Aircraft, Hybrid Electric Propulsion System, Sizing, Non-dominated Sort, NSGA

\section{List of Nomenclature}

$\begin{array}{ll}\rho & \text { Air density } \\ V & \text { Aircraft speed } \\ A R & \text { Aspect ratio } \\ \varepsilon_{b} & \text { Battery energy density } \\ D & \text { Drag } \\ C_{D} & \text { Drag coefficient } \\ \eta_{e l e c} & \text { Electric efficiency } \\ E & \text { Energy } \\ t_{f} & \text { Flight duration } \\ T & \text { Force }\end{array}$

\footnotetext{
* Corresponding author

Email address: ye.xie@cranfield.ac.uk
} 


\begin{tabular}{|c|c|}
\hline$W_{g}$ & Global weight of aircraft \\
\hline$g$ & Gravitational acceleration \\
\hline$C_{L}$ & Lift coefficient \\
\hline$m$ & Mass \\
\hline$\eta_{\text {mech }}$ & Mechanical efficiency \\
\hline$P$ & Power \\
\hline$\sigma_{p}$ & Power-split variable \\
\hline$R_{c}$ & Rate of climb \\
\hline$\varepsilon_{f}$ & Specific fuel consumption \\
\hline$d_{t k o f}$ & Take-off distance \\
\hline$S$ & Wing area \\
\hline$\lambda_{w s}$ & Wing loading \\
\hline \multicolumn{2}{|c|}{ Subscripts } \\
\hline avg & Average \\
\hline batt & Battery \\
\hline $\operatorname{climb}$ & Climb \\
\hline cruise & Cruise \\
\hline$E M$ & Electric motor \\
\hline endur & Endurance \\
\hline fuel & Fuel \\
\hline$I C E$ & Internal combustion engine \\
\hline$L O$ & Lift-off \\
\hline $\max$ & Maximum \\
\hline $\min$ & Minimum \\
\hline range & Range \\
\hline stall & Stall \\
\hline tkof & Take-off \\
\hline
\end{tabular}




\section{Introduction}

Over the last decades, the rapidly growth of fossil fuel consumption has raised concerns regarding emission pollutions and energy sustainability. It also has led to the remarkable increase in oil price. The NASA N+3 has the goal of reducing aircraft fuel burn by as much as $60 \%$ by 2025 [1]. To meet this challenge, the aeronautic industries are showing great interest in electric propulsion systems, including the use of the Electric Motor (EM). However, the energy density of electrical storage devices, such as batteries, is much lower than that of fossil fuels [2]. Currently, electric aircraft cannot achieve the same flight endurance as their conventional (i.e. fossil fuel) powered counterparts and the Internal Combustion Engine (ICE) is still preferred for propelling mid- or long-endurance aircraft.

The Hybrid Electric Propulsion System (HEPS) is a new-generation concept for both aeronautic academics and industries. It combines an electric powertrain with a conventional combustion engine to provide the propulsive power needed. The general outcome is decreased fuel burn compared with ICE-powered only aircraft, and an increased flying range compared with electric aircraft. For these reasons, there is a significant interest in research into this technology and its application to from small to larger-scale aircraft.

Initial research focused on the small-scale (unmanned) sector, to validate the feasibility of hybrid electric technology. The studies carried out at the Air Force Institute of Technology (AFIT), by Harmon [3] and Hiserote [4], concluded that the clutch-start parallel configuration is the most practically realisable. The research team from Queensland University of Technology (QUT) also demonstrated that aircraft performance can be improved by a large margin, as much as 56\% [5] and fuel usage decreased by $6 \%$ [6], with only $5 \%$ weight penalty compared to the non-hybrid system.

The mid-scale aircraft (light manned aircraft) also has attracted much attention. In 2009, the German aircraft builder Flight Design presented a hybrid electric system where a $30 \mathrm{~kW}$ EM provided approximately 5 minutes of additional power to a $86 \mathrm{~kW}$ ICE [7]. Based on this hybrid system, a light aircraft, the EcoEagle was developed by Embry-Riddle Eagle Flight Research Center to compete in NASA's Green Flight Challenge of 2011 [8]. Even though using a parallel configuration, the EcoEagle had the same problem as the Hybrid Atlas (built by University of Cambridge in 2010 [9]). Neither could recharge the battery during flight.

The world's largest aerospace companies are exploring the potential of hybrid-electric technology for large-scale transport aircraft, i.e. regional or even intercontinental airlines. NASA funded the Boeing SUGAR team to boost the promotion of subsonic air transport using hybrid electric concept designs. The 2014 final report demonstrated that hybrid SUGAR Volt could meet the NASA goals regarding fuel burn [10]. Several academic studies [11,12] demonstrated that distributed propulsion could provide substantial performance benefits to blended-wing-body transport aircraft.

The first technological problem to be resolved when introducing hybrid electric technology, is the synergetic design and sizing of the propulsive system at aircraft level. A pioneer of hybrid technology, AFIT, applied conventional aircraft design methods to the sizing of components for a HEPS for Remotely Piloted Aircraft (RPA). Their case studies demonstrate that retrofitting of the existing airframe is possible [13], but fuel saving was not 
demonstrated in the study. For a regional airliner, Delft University of Technology [14], demonstrated a 30\% fuel reduction could be achieved if the battery energy density could be raised to $1000 \mathrm{Wh} / \mathrm{kg}$. Isikveren recommended a so-called quadrant-based algorithmic nomograph to pre-design aircraft with advanced propulsion systems [15]. However, integrated sizing of both propulsion system and aircraft is time-consuming. Thus, Schömann introduced an aircraft scaling approach and focused on the sizing of only propulsion system [16]. The optimization results achieved 5\% fuel mass reduction in hybrid powered aircraft. Researchers are benefitting from sizing only HEPS for existing aircraft [17-19], because the verification of the benefits of hybrid aircraft is a straightforward comparison with the original aircraft. For example, Pornet, et al., claimed that retrofitted hybrid aircraft has the potential to save $16 \%$ fuel-burn for a 900 nautical mile mission [17]. The studies in this paper also begin with the retrofitting of a prototype airframe.

Most studies on the design and sizing of HEPS employ single-objective optimizations. However, a singleobjective (e.g., fuel minimization) can only give one optimal sizing at one specific performance (such as duration), in one optimization run. Therefore, several optimization runs have to be carried out to examine different performance demands $[19,20]$. Multi-objective optimization can simultaneously optimize several objectives and result in Pareto-optimal solutions. Pareto-optimal solutions, or the so-called Pareto front, is the combination of all possible optimal outcomes. If the performance needs are also included in the cost function, the potential of a hybrid propulsion system can be thoroughly evaluated in one optimization run, by using multi-objective optimization. An engineering note about hybrid unmanned aircraft design using multi-objective genetic algorithms was published in 2016 [21], but the authors did not find any full-length-articles in the open literature providing detailed analysis of hybrid aircraft sizing using multi-objective optimization.

This paper is structured as follows. Section 2 completes the problem formulation of the sizing of hybrid electric propulsion systems for prototype aircraft. It starts by first illustrating the performance and mission requirements for the aircraft and propulsion system. Then, the sizing of the hybrid propulsion system is formulated as a multiobjective optimization problem. In Section 3, the new Benchmark based Non-Dominated Sort (BNDS) algorithm is proposed to resolve the established multi-objective optimization problem. Next, BNDS is integrated into the Nondominated Sorting Genetic Algorithm (NSGA). Section 4 presents the Pareto outcomes of the BNDS/NSGA and the sensitivity of optimization results. The performance of the retrofitted hybrid aircraft is validated by comparison with the prototype.

\section{Propulsion System Sizing}

In this section, the system sizing techinque is applied to design a hybrid electric propulsion system for the prototype aircraft. The section first analyses the performance requirements of the retrofitted aircraft and HEPS. The power-weight models of different engines and motors are also established and compared. An overview of the structure of HEPS is presented. The system sizing of HEPS is then formulated into a multi-objective optimization problem, in which the objectives, optimized variables and constraints are illustrated. 


\subsection{Aircraft Performance}

The prototype aircraft is developed based on Ercoupe, first manufactured by the Engineering and Research COrporation (ERCO). It is a low-wing monoplane aircraft as shown in Fig. 1, and usually equipped with a Continental combustion engine of $48 \mathrm{~kW}$ to $67 \mathrm{~kW}$ (64-hp to 89-hp).

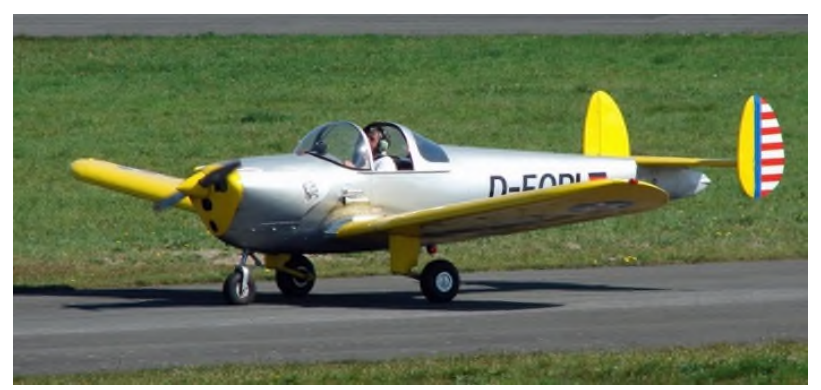

Fig. 1 ERCO Ercoupe 415 [22].

For this project, a Continental C-75-12 powered model was selected as the template of a prototype aircraft. The basic properties of the prototype and its performance are given in Table 1. The Maximum Take-Off Weight (MTOW) is $572 \mathrm{~kg}$ when the $56 \mathrm{~kW}$ (75-hp) Continental engine is used.

Table 1 Basic properties

\begin{tabular}{llll}
\hline \hline Prototype Aircraft & & Symbol & Value \\
\hline Airframe & Wingspan & - & $9.1 \mathrm{~m}$ \\
& Length & - & $6.3 \mathrm{~m}$ \\
& Wing area & $S$ & $13.3 \mathrm{~m}^{2}$ \\
& Wing loading & $\lambda_{w s}$ & $43 \mathrm{~kg} / \mathrm{m}^{2}$ \\
Performance & Maximum speed & - & $177 \mathrm{~km} / \mathrm{h}$ \\
& Stall speed & $V_{\text {stall }}$ & $77 \mathrm{~km} / \mathrm{h}$ \\
& Rate of climb & $R_{c}$ & $2.8 \mathrm{~m} / \mathrm{s}$ \\
& Take-off distance & $d_{\text {tkof }}$ & $230 \mathrm{~m}$ \\
Others & Duration & $t_{f}$ & $2-3 \mathrm{~h}$ \\
& MTOW & $W_{g}$ & $572 \mathrm{~kg}$ \\
& Engine maximum power & $P_{I C E, \max }$ & $56 \mathrm{~kW}$ \\
\hline \hline
\end{tabular}

\subsubsection{Requirements}

The aircraft when retrofitted will be required to meet a number of performance targets. The first will be that the endurance speed will have an adequate safety margin above the stall speed. The endurance speed and stall speed can be calculated by:

$$
V_{\infty}=\sqrt{\frac{2 W_{g}}{\rho_{\infty} C_{L} S}}
$$


using the corresponding parameters for the steady-level flight at endurance and stall speed, respectively. $S$ denotes wing area and $W_{g}$ represents the global weight.

Secondly, the minimum and maximum power requirements also need to be determined, and for steady-level flight, the power requirement is expressed by:

$$
P_{r d}=\sqrt{\frac{2 W_{g}^{3}}{\rho_{\infty} S}} \cdot \frac{C_{D}}{C_{L}^{3 / 2}}
$$

Thus the power needed for different airspeeds can be found. The power at the endurance speed is the minimum power demand for flight, i.e. $P_{\min }=P_{\text {endur }}$.

On the other hand, the maximum power requirement depends on the take-off and climbing performance, mainly featured by the take-off roll and Rate of Climb (RoC).

For a reciprocating engine/propeller combination, the power is reasonably constant during the take-off phase. Neglecting the rolling resistance and using average thrust and drag, the take-off distance can be expressed as:

$$
d_{t k o f}=\frac{W_{g} V_{L O}^{2}}{2 g\left(T_{a v g}-D_{a v g}\right)}
$$

where $g$ is acceleration of gravity. The lift-off velocity, $V_{L O}$, should be no less than $1.1 V_{\text {stall }}$ [23]. $T_{\text {avg }}$ and $D_{\text {avg }}$ are equal to their values at $0.7 V_{L O}$, respectively. Take-off power $P_{t k o f}$ can be estimated using $P_{t k o f}=T_{a v g} \cdot 0.7 V_{L O}$.

Climbing to a higher altitude at a specific rate is another important characteristic for evaluating aircraft performance. $R_{c}$ is a function of excess power, which is the difference between available power $\left(P_{c l i m b}\right)$ and the power required to overcome drag $\left(P_{r d}\right)$ :

$$
R_{c}=\frac{P_{c l i m b}-P_{r d}}{W_{g}}
$$

Here, the power demanded for cruising, $P_{\text {cruise }}$, not minimum power required, is taken to represent the power required $\left(P_{r d}\right)$. Thus, the power available for climbing can be addressed by: $P_{\text {climb }}=P_{\text {cruise }}+R_{c} \cdot W_{g}$.

The range speed is the speed giving greatest fuel economy, but is too slow for ideal cruising. This paper introduces Carson's Speed as the optimum cruising speed, defined as "the least wasteful way of wasting fuel" [24]. Unless otherwise stated, the cruising speed, $V_{\text {cruise }}$ used in the paper will be the Carson's Speed. The relation between Carson's Speed and the range speed is $V_{\text {cruise }}=3^{1 / 4} V_{\text {range }}$ [24].

\subsubsection{Weight Models}

From Eqs. (1)-(4), it is seen that all aspects of the aircraft's performance depend on its global weight, which consists mainly of propulsion system weight and airframe, with other devices. Different from the conventional propulsion system, an HEPS includes both engine and electric motor. The weight of each of these increases with power capability. 
This study compares the weight models as a function of maximum power, between two types of reciprocating engines. As shown in Fig. 2, the rotary engine has higher power-to-weight ratio than the piston engine with 1-3 cylinders, when the engine output capability is under $100 \mathrm{~kW}$. Between $30 \mathrm{~kW}$ and $90 \mathrm{~kW}$, four-cylinder piston engines tend to be favoured due to its low torque fluctuation, compared with 1-3 cylinders. However, few 3-4 cylinders are used in rotary engines in this power range, since the rotary engine can achieve smooth operation with only 1-2 cylinders.

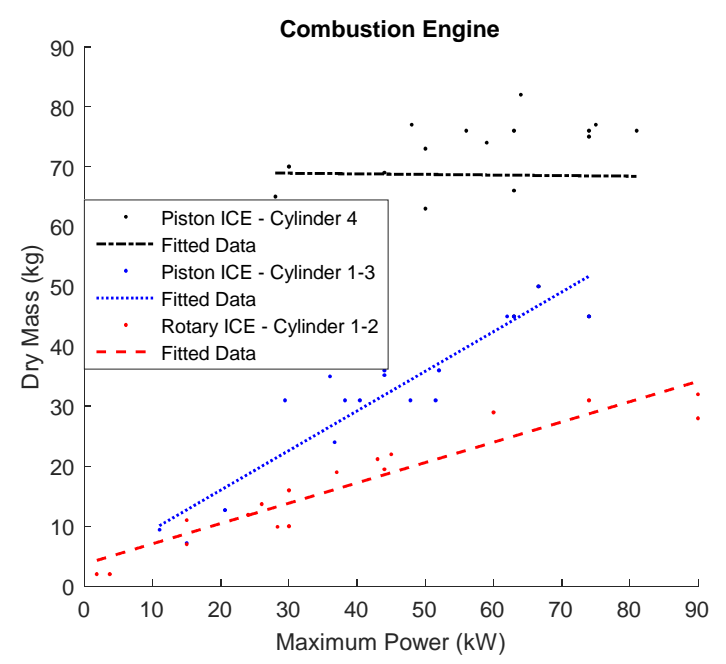

Fig. 2 Comparison of weight model for different engines.

Concerning electric motors, it is well known that BrushLess Direct Current motor (BLDC) and Permanent Magnet Synchronous Motor (PMSM) have better efficiency and power density than other types of electric motors [25]. The weight models of several BLDC and PMSM from different companies are given in Fig. 3(a). The maximum voltage of selected BLDC is between $600-800 \mathrm{~V}$, and its maximum rotational speed is around $3000 \mathrm{rpm}$ when without load. On the other hand, the maximum voltage of selected PMSM is $600 \mathrm{~V}$, and the maximum no-load $\mathrm{rpm}$ is around 5000 .

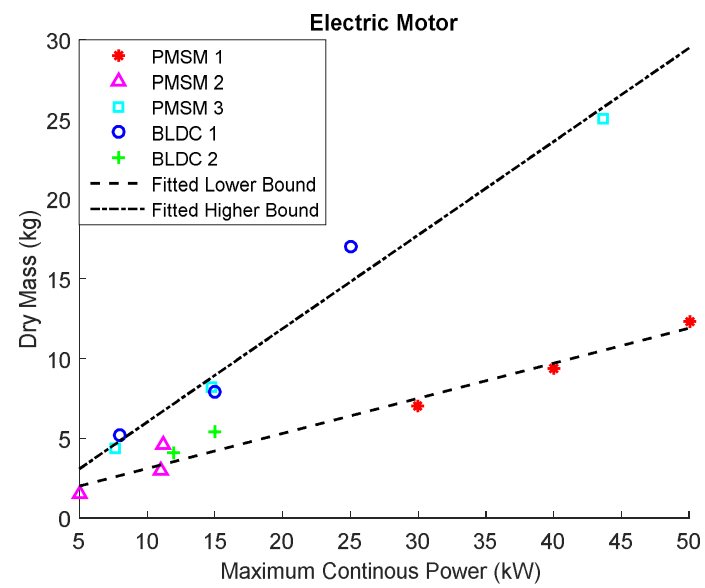

(a)

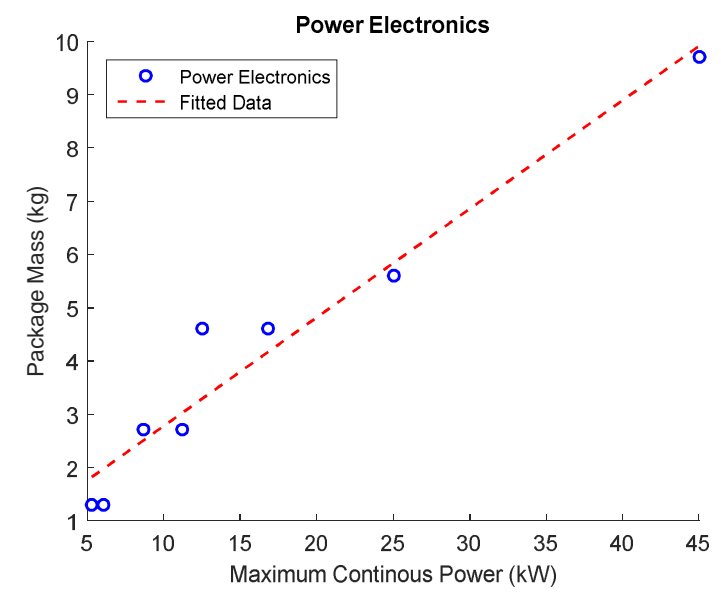

(b)

Fig. 3 Weight model for electric motor and its power electronics. 
Regarding off-the-shelf motors, the PMSM can usually achieve higher maximum power output than the BLDC, as shown in Fig. 3(a). The electric motors from different companies normally have different power densities, but products from the same company show similar values. The fitted lower boundary in the graph implies the highest power density the BLDC/PMSM can achieve; and vice versa. On the other hand, the weight of power electronics cannot be ignored for high-voltage or -current motors. The weight model fitted results of power electronics are shown in Fig. 3(b).

In a word, for prototype aircraft as used in this study, the rotary engine is more appropriate than a piston engine, regardless of number of cylinders. The PMSM was chosen as having the highest-power-density.

\subsection{Propulsion System Architecture}

There are various hybrid powertrain configurations currently in use. The most commonly used are; series, seriesparallel and parallel architectures. Of these, the series architecture enables the engine to operate at its ideal operating condition. However, its system efficiency is relatively low since large energy losses exist in the energy conversion [2]. The series-parallel is the most functional structure of the three, but its complicated clutch/gear mechanism raises the issue of reliability in aircraft applications. Compared with the series-parallel configuration, the parallel configuration is lighter and less complex. According to work by Harmon [3] and Hiserote [4], the parallel configuration is best suited for mid-scale aircraft.

The HEPS was thus designed with a parallel architecture, see Fig. 4 for a schematic of its high-level structure. For structure simplicity the engine has a start motor. Integral with the engine is a generator to power the on-board electrics. The engine's output shaft drives the motor/generator's input shaft via a clutch mechanism and the motor/generator's output shaft drives the propeller. The motor driving the propeller is supported by power supplied by the battery which can be re-energized when the motor acts as a generator. Here, if the voltage supplied by the battery is $600 \mathrm{~V}$, the maximum rotational speed of the motor/generator may exceeds $5000 \mathrm{rpm}$. Therefore, a lowervoltage, i.e., $300 \mathrm{~V}$ battery would avoid the need for a gear between motor/generator and propeller.

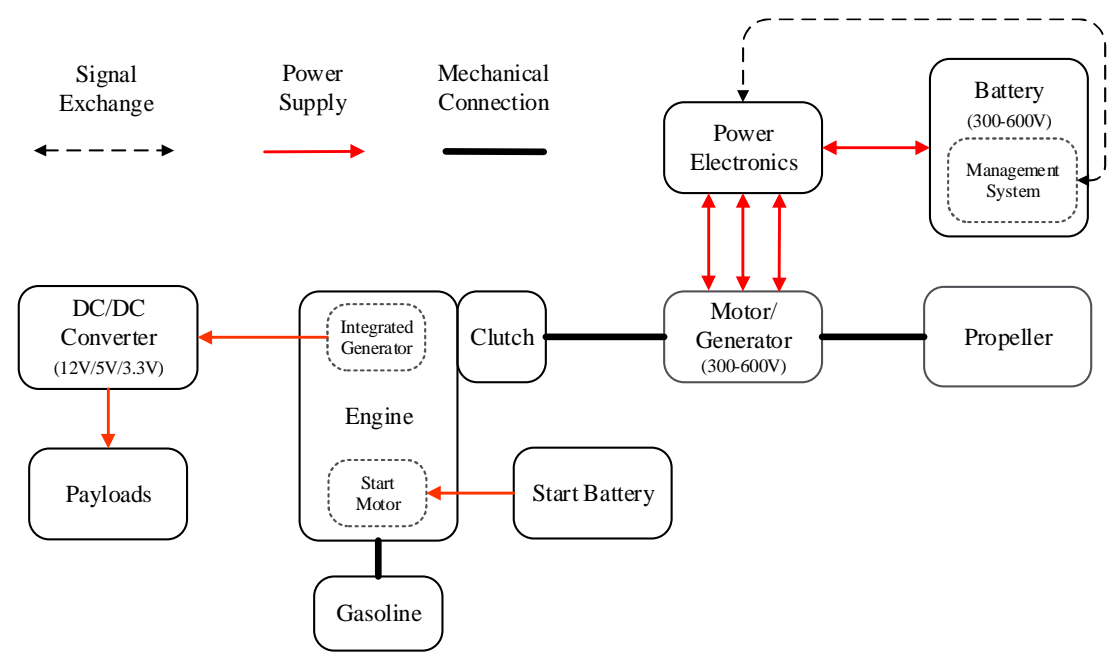

Fig. 4 Parallel hybrid electric propulsion system 


\subsection{Objectives and Variables}

Different from the traditional propulsion system, the hybrid has two additional parameters that determine its capability—hybrid of power and hybrid of energy. The former is also called Degree of Hybridization (DoH) [26], which compares the maximum installed power of engine and electric motor. The latter shows the ratio of energy storage of fuel and battery. In other words, the maximum power of engine and electric motor, and the energy storage of fuel and battery must be taken as the variables to be optimized. It is more common to refer to the mass of the fuel rather than its energy content since the former provides a more straightforward representation of fuel consumption. Therefore, the mass of fuel and battery are considered as the optimized variables, replacing the energy storage of fuel and battery, respectively.

The fuel mass of a flight mission cycle can be presented as:

$$
m_{\text {fuel }}=\int_{0}^{t_{f}} \dot{m}_{\text {fuel }}\left(P_{I C E}\right) d t
$$

where $\dot{m}_{f u e l}$ is the rate of fuel consumption and $t_{f}$ is the time of flight.

Fig. 5 presents the flight mission cycle considered in this paper. The duration of the flight, $t_{f}$, will be set as a variable to be optimized, i.e. maximized. The rate of power demanded, $P_{r e q}$, will be different for the different phases of the flight mission cycle. From Eq. (5), the total fuel consumption depends on the power drawn from the engine. The instantaneous engine power $P_{I C E}$ is generally related to the power requirement $P_{\text {req }}$ using the power-split variable $\sigma_{p}$, and so $\sigma_{p}$ has to be considered as variable to be optimized. Note that $\sigma_{p}$ is time-variant and $P_{I C E}(t)=$ $\left(1-\sigma_{p}(t)\right) \cdot P_{r e q}(t)$.

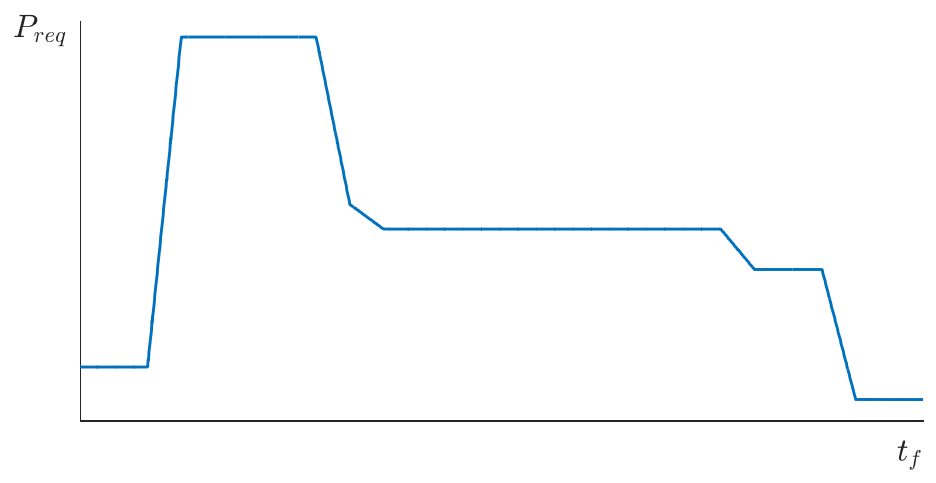

Fig. 5 Flight mission cycle.

Eq. (5) shows that one can minimize fuel consumption by reducing either or both flight duration $t_{f}$ and engine power $P_{I C E}$. However, the flight time is a variable that every designer desires to maximize. Thus, fuel consumption $m_{f u e l}$ and flight duration $t_{f}$ should be considered as contradictory objectives. 
In brief, the optimized variables consist of the maximum engine power $P_{I C E, \max }$, the maximum motor power $P_{E M, \text { max }}$, fuel mass $m_{f u e l}$, battery mass $m_{\text {batt }}$, flight duration $t_{f}$, and power-split variable $\sigma_{p}$. This paper defines two objective functions as:

$$
\begin{aligned}
& \min J_{1}=m_{f u e l} \\
& \min J_{2}=-t_{f}
\end{aligned}
$$

\subsection{Constraints}

One constraint on sizing hybrid propulsion systems is that the performance of prototype aircraft cannot be sacrificed. In other words, the retrofitted aircraft should achieve a higher RoC and shorter take-off distance, or at least the same values. MTOW and airspeed are also constrained. Further, the retrofitted aircraft must meet mission requirements, such as the electric-only flight and the battery charge. Therefore, a certain amount of on-board fuel and electrical energy is needed to complete the whole flight mission cycle. In total, these performance and mission requirements can be summed as: airspeed requirement, wing loading constraint, power requirements, and energy requirements. Each of these will be governed by the inequality constraints expressed in Eqs. (7)-(13).

Typical stall and endurance speeds are not fixed, but the endurance speed has to be greater than the stall speed and the margin between those two values has to be maintained (see Eq. (7)). For retrofitted aircraft, the MTOW is allowed to be greater than for a prototype, subject to the condition shown in Eq. (8), that the wing loading of the retrofitted aircraft is less than the maximum desired value. Eq. (9) guarantees that the combination of the maximum engine and motor power can satisfy the take-off and climbing requirements. $\eta_{\text {air }}$ is an altitude-related factor for correcting the engine output capability. The electric system efficiency, $\eta_{\text {elec }}$, consists of motor efficiency and battery efficiency. $\eta_{\text {mech }}$ represents mechanical efficiency mainly affected by the propeller. Eq. (10) means that the electric motor can power the aircraft by itself. Eq. (11) requires the engine to be able to output sufficient power to charge the battery while the aircraft is cruising. The value of $\sigma_{p}$ will determine the required charge power. With regards to Eqs. (12) and (13), $E_{f u e l}$ and $E_{\text {batt }}$ denote the consumed fuel and battery energy, respectively. $\varepsilon_{f}$ is the Specific Fuel Consumption (SFC) of the engine, while $\varepsilon_{b}$ is the energy density of the battery.

$$
\begin{gathered}
V_{\text {stall }}+\Delta V \leq V_{\text {endur }} \\
\frac{W_{g}}{S} \leq \lambda_{\text {ws,max }} \\
\left(P_{I C E, \text { max }} \cdot \eta_{\text {air }}+P_{E M, \text { max }} \cdot \eta_{\text {elec }}\right) \cdot \eta_{\text {mech }} \geq \max \left\{P_{\text {takof }}, P_{\text {climb }}\right\} \\
P_{E M, \text { max }} \cdot \eta_{\text {elec }} \cdot \eta_{\text {mech }} \geq P_{\text {min }} \\
P_{I C E, \text { max }} \cdot \eta_{\text {air }} \cdot \eta_{\text {mech }} \geq \max \left\{P_{\text {cruise }} \cdot\left(1-\sigma_{p}(t)\right)\right\}
\end{gathered}
$$




$$
\begin{gathered}
m_{\text {fuel }} \geq \frac{E_{\text {fuel }}}{\eta_{\text {air }} \cdot \eta_{\text {mech }}} \cdot \varepsilon_{f} \\
m_{\text {batt }} \geq \frac{E_{\text {batt }}}{\eta_{\text {elec }} \cdot \eta_{\text {mech }}} \cdot \frac{1}{\varepsilon_{b}}
\end{gathered}
$$

The calculations of consumed fuel and battery energy are addressed by Eqs. (14) and (15). The total consumed fuel energy is equal to the sum of instantaneous engine power during the flight. The battery energy storage not only includes the sum of the electric power, but also the additional usage necessary for emergency condition, such as engine failure. The power requirement, $P_{r e q}(t)$, in Eqs. (14) and (15) changes with the different flight phases of the mission cycle. For example, $P_{\text {req }}(t)=P_{\text {climb }}$ during the climbing period. $t_{\text {emerg }}$ stands for the time duration for safe-landing using electric power source. It can also be considered as the time required for continuous electric-only flight.

$$
\begin{gathered}
E_{\text {fuel }}=\int_{0}^{t_{f}}\left(P_{I C E}(t)\right) d t=\int_{0}^{t_{f}}\left(P_{\text {req }}(t) \cdot\left(1-\sigma_{p}(t)\right)\right) d t \\
E_{\text {batt }}=\int_{0}^{t_{f}}\left(P_{E M}(t)\right) d t=\int_{0}^{t_{f}}\left(P_{\text {req }}(t) \cdot \sigma_{p}(t)\right) d t+\int_{0}^{t_{\text {emerg }}}\left(P_{\text {min }}\right) d t
\end{gathered}
$$

\section{Non-dominated Sorting Genetic Algorithm}

The optimization algorithm used in this paper is based on an open source NSGA-II program by Aravind Seshadri [27]. A new BNDS algorithm is proposed and developed to replace the Fast Non-dominated Sorting (FNS) approach of Kalyanmoy Deb [28]. The benefits and computational complexity of BNDS are illustrated. Also, the constraint handling is incorporated into the NSGA-II program.

\subsection{BNDS}

Non-dominated sorting is a procedure where solutions in the population are assigned to different Pareto fronts based on their dominance relationships. It plays a critical role in the sorting operations of the NSGA. A common problem of non-dominated sorting algorithms is the intensive computation required during the sorting process [29]. A newly developed non-dominated sorting algorithm, called BNDS, is proposed in this paper, to reduce the computational complexity.

The Hierarchical Non-Dominated Sort (HNDS) algorithm was proposed in 2017 [30]. The HNDS first sorts all candidate solutions in ascending order by their first objective. Then it compares the first solution with all others, one by one to make a rapid distinction in order to decide if this solution belongs to the current front. The HNDS was

shown to be more computationally efficient than the FNS, Arena's principle and deductive sort. The operation of HNDS is illustrated as follows. 
Before conducting the sorting algorithm, the $n$ solutions in the population $P$ are sorted in an ascending order according to the first objective value. The sorted solution is contained in the set $Q$. If the first objective values of two solutions are the same, then they are sorted according to the second objective value. This procedure continues until all individuals in the population are sorted. If solutions have the same value in all objectives, their order can be arbitrary. Since all the solutions are sorted by one objective, the following conclusions can be inferred: 1) the first solution must belong to the current front; 2) the succeeding solution can never dominate the preceding solution; 3) if a succeeding solution is not dominated by the preceding solution, the remaining objectives of this succeeding solution cannot be worse than the remaining objectives of the preceding solution.

To find the solutions in the set $Q$ that belongs to the current front $F_{k}$, HNDS divided the comparison into several rounds. In the first round, the algorithm assigns the first solution to the current set and compares the first solution with all succeeding solutions. The succeeding solutions dominated by the first solution are discarded and allocated to the set $R$, since they are determined to not belong to the current front. On the other hand, the solutions not dominated by the first solution need another round to determine if they belong to this front. The algorithm moves these non-dominated solutions to a new set $Q$ and starts the second round comparison. The same procedures as the first round are performed in the second round. More discarded solutions are transferred to the set $R$ and another new set $Q$ is created for the third round comparison. This comparison loop will be repeated until the new set $Q$ becomes empty. All solutions in the current front are identified during each round. To start the determination of the next front, the solutions in set $R$ is assigned to the set $Q$.

HNDS can avoid large numbers of dominance comparisons between solutions in different fronts. However, it still performs many unnecessary comparisons, since it enforces the comparisons between the first solution and all succeeding solutions. In this study, the idea of the benchmark solution is proposed to reduce the unnecessary comparisons further. Our algorithm can also be classified into several rounds. In the first round, the first solution in the set $Q$ is included in the current front and selected as the benchmark solution. Different from HNDS, the first solution will be compared with the succeeding solutions until the first non-dominated solution occurs. Then, this non-dominated solution is included in the current front and assigned as the new benchmark solution, which means that the second round comparison starts. The loop end condition is the same as for the old algorithm. The pseudocode of the new non-dominated sorting algorithm is presented in Table 2.

Table 2 BNDS

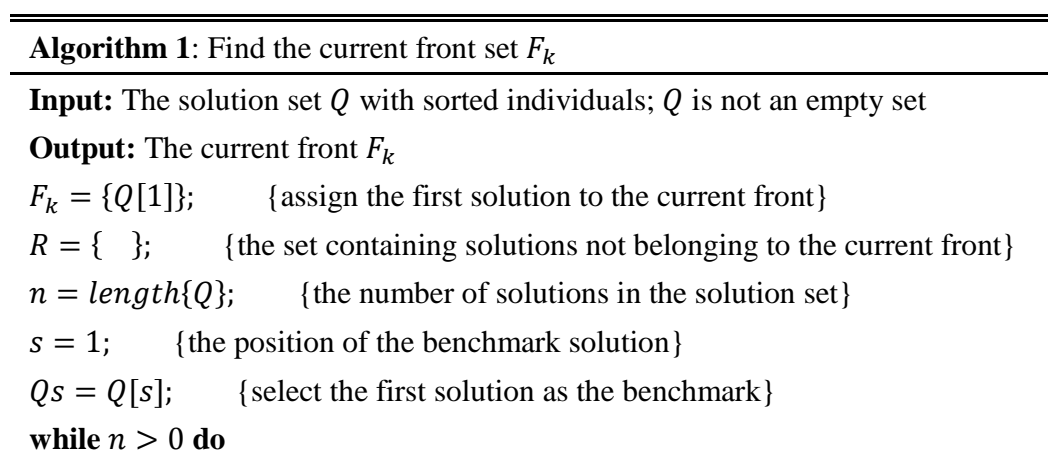




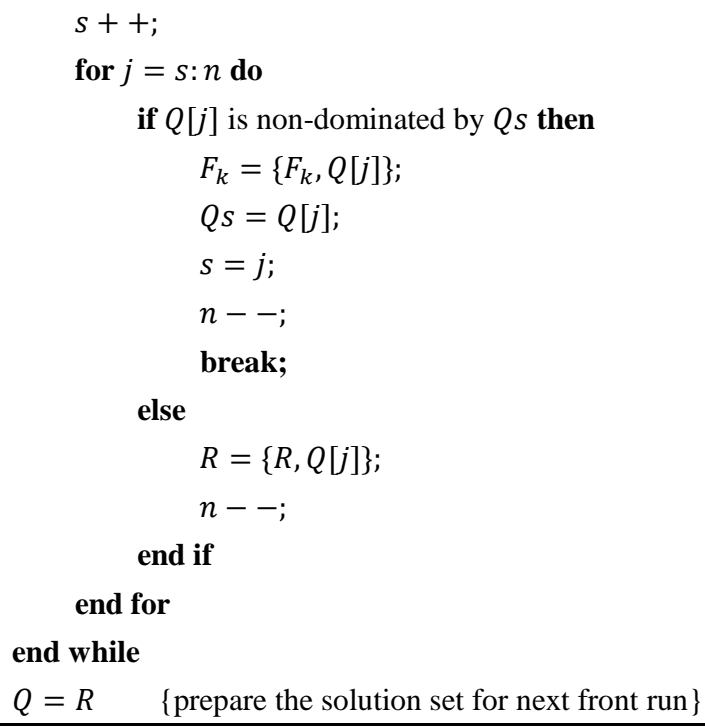

BNDS has several advantages, in addition to HNDS: 1) at each round of comparisons, creating a new set $Q$ is no longer needed; 2) BNDS will not change the sequence of the solutions in the set $R$, overcoming the drawback of HNDS; 3) many unnecessary comparisons are further avoided, since each benchmark solution does not need to be compared with all succeeding solutions; 4) BNDS is friendly to the comparison between the identical solutions, since the succeeding solution can replace the preceding one to be the new benchmark solution.

The time complexity of BNDS consists of two main parts. First, the initial population is sorted in ascending order according to the first objective. Second, the solutions in the sorted population are compared and assigned to different fronts. The time complexity of the first step is $O(N \log N)$ if 'Merge Sort' is applied. Regarding the second step, the worst case happens when every solution in the sorted population belongs to different fronts and is dominated by all preceding solutions. In this case, all solutions have to be compared with each other, so the worst time complexity is $O\left(M N^{2}\right)$. For the best case, all solutions in the sorted population are non-dominated by each other and can be assigned to one front. Put differently, each solution only needs to be compared with the one next to it in the sorted population, so the best time complexity is $O(M N)$.

\subsection{Constraint Handling}

The constraint is traditionally handled with the Lagrangian function using the penalty term. If constraints are treated as another cost when implementing non-dominated sorting, the penalty term can be removed. The definition of domination is adjusted so that the solution with a smaller constraint violation has a better rank and feasible solutions always dominate infeasible solutions.

The pseudo-code of constrained, non-dominated sorting is provided in Table 3. Before the while loop of Algorithm 2, the initial population $P$ is separated into the feasible part $Q$ and infeasible part $I$. The front set $F$ is set to be empty. The fronts of feasible solutions $Q$ can be acquired by implementing the while loop. The while loop will call Algorithm 1 to sort out each front $F_{k}$, until the solution set $Q$ becomes empty. The executing condition of the 
while loop is realizable since Algorithm 1 will update the solution set $Q$ at each loop. When every solution is assigned to one front, the loop ends. Especially, the executing condition of the while loop also ensures that the set $Q$ used in the Algorithm 1 is not empty. Finally, all infeasible solutions are considered to belong to one front, so the set $I$ can be attached at the end of front set $F$.

Table 3 Constrained non-dominated sorting algorithm

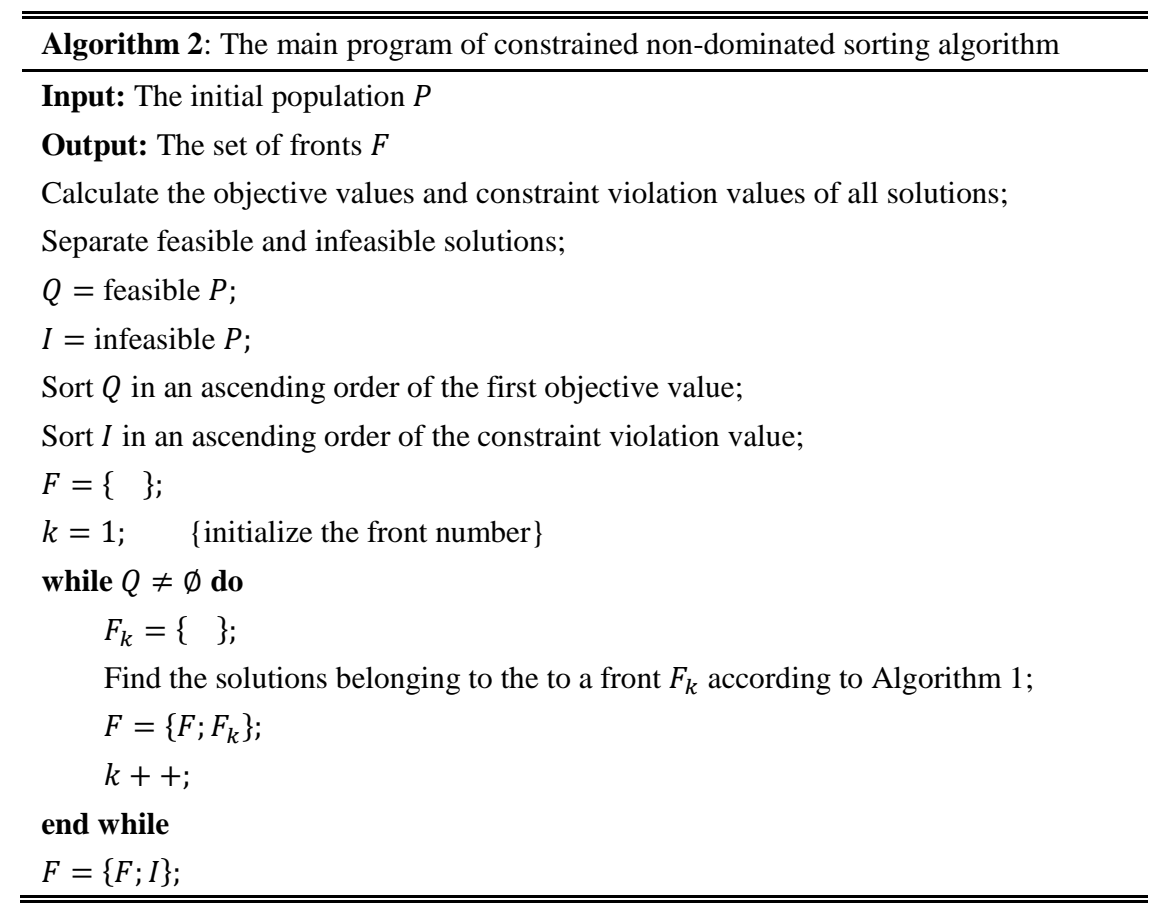

Fig. 6 presents the flow chart for the BNDS/NSGA algorithm, with BNDS and constraint handling included. First, the population $P$ is initialized, then in a second step is separated into feasible solutions (part $Q$ ) and infeasible solutions (part $I$ ). Next, the values of objective functions are determined so the set $Q$ can be sorted according to the first objective value; then the constraint violations are calculated, so the set $I$ can be sorted according to the constraint violation value. The feasible solution set, $Q$, is sorted using the proposed BNDS method. The sorted feasible front set $F$ is combined with the sorted infeasible solution set $I$. The final front set of the population $P$ is $\{F ; I\}$. In the front set $\{F ; I\}$, the parent solutions are selected to generate the offspring individuals. The offspring individuals are attached to the original population $P$ and the new population $P$ is generated. The next loop of the BNDS/NSGA algorithm begins by replacing the old population with the new population, $P$. This process continues until the termination criterion is satisfied, for example that the loop count reaches a maximum value, or the average change in the spread of fronts is less than the tolerance. Lastly, the first front $F_{1}$ of the final front set is acquired as the Pareto front. 


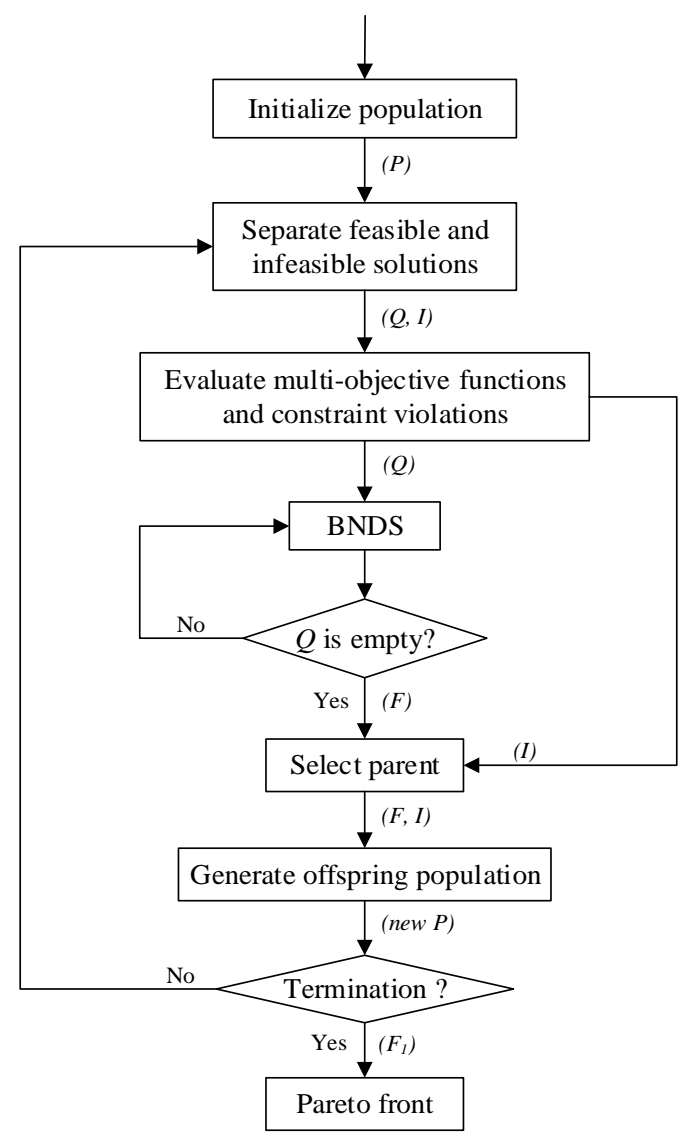

Fig. 6 Non-dominated sorting genetic algorithm with BNDS and constraint handling.

\section{Optimization Results}

In this paper, the optimization sizing of the hybrid propulsion system considers the two objectives: fuel consumption and flight duration. BNDS/NSGA results in a series of feasible solutions that represent the best tradeoff between the two objectives. Those solutions do not dominate each other, and the set of them is called a Pareto front or Pareto frontier. This section presents and validates the Pareto front and retrofitted hybrid aircraft. The sensitivity of optimization results to emergency time and battery energy density are also analysed.

The boundaries of the optimized variables are provided in Table 4. The maximum power of neither engine nor motor are allowed to exceed those of the prototype engine, though the total installed power, the sum of $P_{I C E, \max }$ and $P_{E M, \max }$, can be greater than for the prototype. The upper bound of fuel and battery mass is the useful load mass of the prototype aircraft, while the lower bound of battery mass is equal to the prototype battery mass. The feasible value of the duration $t_{f}$ is not limited to between $2-3 \mathrm{~h}$, instead a wider range (from $1 \mathrm{~h}$ to $4 \mathrm{~h}$ ) is applied to search more possibilities. The maximum value of the power split $\sigma_{p}$ cannot be greater than 1 based on the definition of $\sigma_{p}$. On the other hand, when the $\sigma_{p}$ is negative, the battery charge is on using the engine power. Since part of the engine 
power should be used to power the aircraft, the power used for battery charging cannot be too high. Considering this, the minimum value $\sigma_{p}$ is set to -10 .

Table 4 Variable bounds

\begin{tabular}{lll}
\hline \hline Variable & Lower Bounds & Upper Bounds \\
\hline$P_{I C E, \max }$ & 0 & $56 \mathrm{~kW}$ \\
$P_{E M, \max }$ & 0 & $56 \mathrm{~kW}$ \\
$m_{\text {fuel }}$ & 0 & $233 \mathrm{~kg}$ \\
$m_{\text {batt }}$ & $20 \mathrm{~kg}$ & $233 \mathrm{~kg}$ \\
$t_{f}$ & $1 \mathrm{~h}$ & $4 \mathrm{~h}$ \\
$\sigma_{p}$ & -10 & 1 \\
\hline \hline
\end{tabular}

The parameters needed are listed in Table 5, reflecting other system requirements and component features. The minimum margin between stall and endurance speed, $\Delta V$, is $13 \mathrm{~km} / \mathrm{h}$, the minimum time for emergency landing using only electrical energy is $20 \mathrm{~min}$. The maximum value of desired wing loading is $50 \mathrm{~kg} / \mathrm{m}^{2}$. The energy density of Lithium-ion batteries is generally between $110 \mathrm{Wh} / \mathrm{kg}$ and $240 \mathrm{Wh} / \mathrm{kg}$, while some high-performance cells can be as high as $260 \mathrm{Wh} / \mathrm{kg}$ [31]. Here, an average value of $180 \mathrm{Wh} / \mathrm{kg}$ was chosen to study the general situation.

Table 5 Parameters

\begin{tabular}{lll}
\hline \hline & Symbol & Value \\
\hline Requirement & $\Delta V$ & $13 \mathrm{~km} / \mathrm{h}$ \\
& $t_{\text {emerg }}$ & $20 \mathrm{~min}$ \\
& $\lambda_{\text {ws,max }}$ & $50 \mathrm{~kg} / \mathrm{m}^{2}$ \\
Component & $\varepsilon_{b}$ & $180 \mathrm{Wh} / \mathrm{kg}$ \\
\hline \hline
\end{tabular}

\subsection{Pareto Front}

The Pareto optimal outcomes in Fig. 7 show optimal trade-offs of fuel consumption and flight duration. Each point (solution) represents the minimum fuel used at the corresponding flight duration. When the duration boundary is restricted to between $1 \mathrm{~h}$ and $4 \mathrm{~h}$, the fuel mass varies from $15 \mathrm{~kg}$ to $50 \mathrm{~kg}$. Obviously, higher fuel usage is needed to complete longer duration flights. 


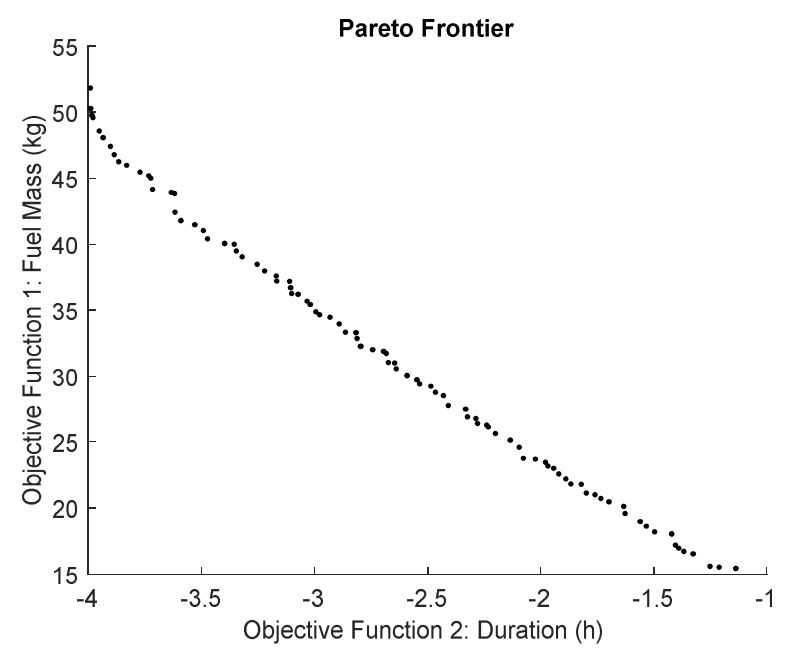

Fig. 7 Pareto frontier.

The optimal values of flight duration, the maximum engine power and the maximum motor power are given by Fig. 8. The figure presents the relationships between those optimized variables and the fuel mass. It is clear from Fig. 8(a) that the flight duration increases with fuel usage and reaches $4 \mathrm{~h}$ about $50 \mathrm{~kg}$ fuel consumption. On the other hand, Fig. 8(b) shows that the optimal values of maximum motor and engine power do not vary substantially with change of fuel mass. That is, fuel mass is only weakly correlated to maximum motor or engine power. As flight duration is strongly and positively correlated to fuel mass, it must also be only weakly related to the maximum motor and engine power. It follows that maximum motor and engine power have little effect on the two objectives (fuel mass and flight duration).
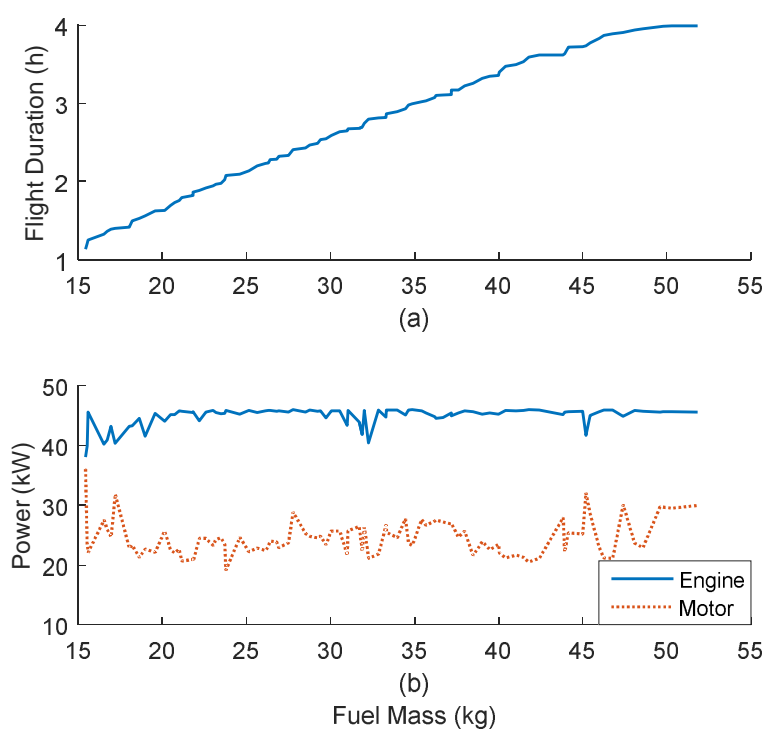

Fig. 8 Flight duration and maximum engine/motor power vs. fuel mass.

Fig. 9 shows hybrid of power (DoH) and hybrid of energy as functions of fuel mass. As would be expected, DoH is only weakly related to the fuel mass, since it is the ratio of the maximum motor power to the maximum HEPS power. Clearly from Fig. 9(a), there is no significant or consistent change in DoH with change in fuel mass. On the 
other hand, hybrid of energy decreases as fuel mass increases from $15 \mathrm{~kg}$ to above $50 \mathrm{~kg}$. It appears that there is a decrease in electrical energy with increase in mass of fuel installed on-board; contra-wise it appears that increased electrical energy reduces the flight duration, since the flight duration has the same trend as the fuel consumption.
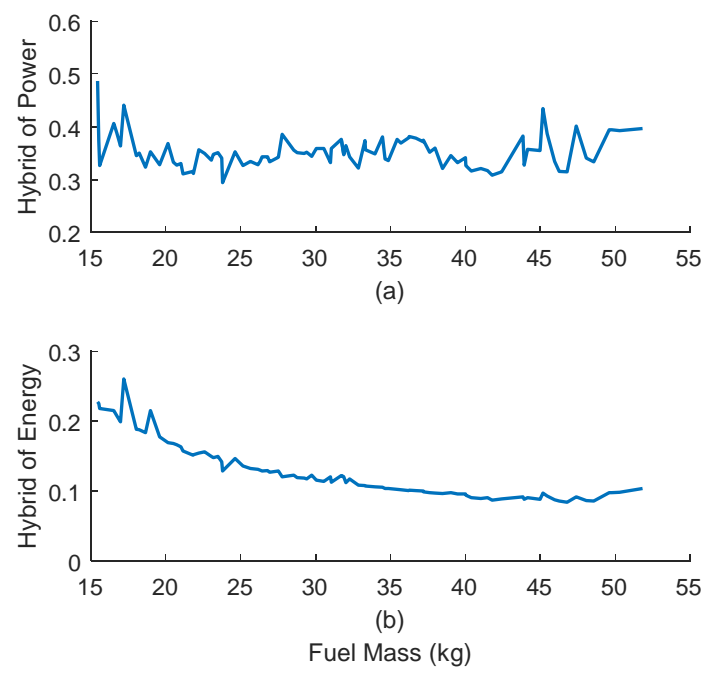

Fig. 9 Hybrid of power and hybrid of energy vs. fuel mass.

\subsection{Comparison}

This section estimates the fuel saving performance for each solution of the Pareto front. Each solution of the Pareto front represents one non-dominated optimal result of a retrofitted hybrid aircraft and HEPS. The fuel saving performance of every solution (hybrid aircraft) is presented by the percentage of fuel saving. The percent of fuel saving is calculated by comparing the fuel mass of the hybrid aircraft (each solution of the Pareto front) and the fuel mass of the prototype aircraft.

The endurance and range of each solution of the Pareto front, as functions of fuel saving, are given in Fig. 10, except those with negative fuel saving percent. It is clear that both the endurance and range decease when the fuel saving increases. The endurance of hybrid aircraft can be up to $6 \mathrm{~h}$ if the hybrid aircraft carries the same mass of fuel as the prototype. Similarly, a range of over $600 \mathrm{~km}$ can be achieved with zero fuel saving. On the other hand, if the maximum fuel saving (about 65\%) is desired, the hybrid aircraft only has $2 \mathrm{~h}$ endurance and $200 \mathrm{~km}$ range.

The original range and endurance of the prototype were approximately $500 \mathrm{~km}$ and $5 \mathrm{~h}$, respectively. If the range and endurance of the hybrid are not sacrificed with respect to the prototype, the maximum increase in fuel economy is $17.6 \%$. Note that the energy used by the hybrid aircraft not only includes the fuel but also the electrical energy stored in the battery. The total energy saving is $12.5 \%$ for the same solution with $17.6 \%$ fuel reduction. This indicates that the fuel consumption of the hybrid aircraft is reduced not only due to the fact of external electrical energy usage. 

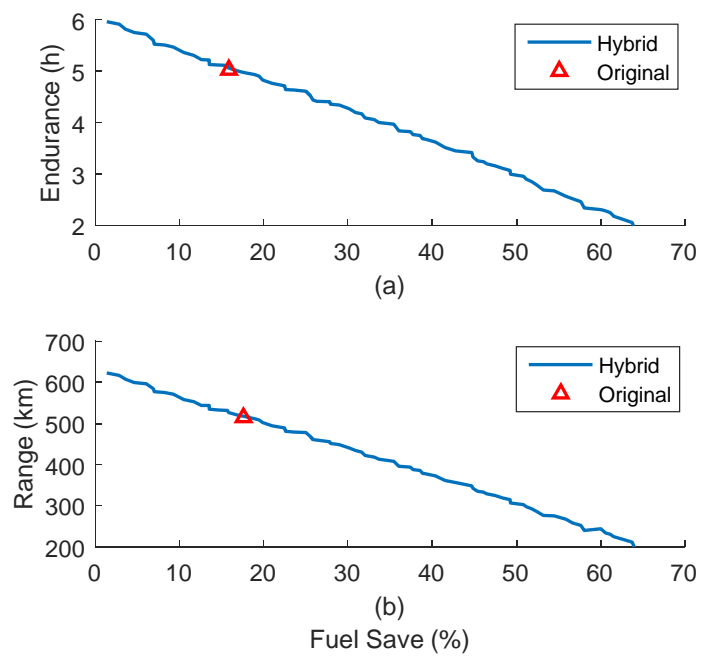

Fig. 10 Endurance and range vs. fuel saving.

The above-mentioned solution is set as the preferred solution, which achieves the minimum fuel consumption without compromise of endurance and range. This solution gives the variables and parameters of the retrofitted hybrid aircraft and the hybrid propulsion system. The details of HEPS and its retrofitted aircraft are listed in Table 6.

The power capability of the hybrid propulsion system is higher than the original, with combined engine and electric motor power. Therefore, the hybrid propulsion system can provide the potential for larger take-off weight $(603 \mathrm{~kg})$. Most of the additional weight is used to carry a large battery $(84 \mathrm{~kg})$, since the needed fuel weight $(32 \mathrm{~kg})$ are less than one of the prototype aircraft $(43 \mathrm{~kg})$. It is worth mentioning that the real load capability $(190 \mathrm{~kg})$ is not sacrificed when using the hybrid propulsion system, since the fuel is generally considered as part of the load.

Table 6 Comparison between prototype and hybrid powered aircraft

\begin{tabular}{llll}
\hline \hline & & Prototype & Hybrid \\
\hline Maximum Propulsion & Engine Power & $56 \mathrm{~kW}$ & $40 \mathrm{~kW}$ \\
System Power & Motor Power & 0 & $30 \mathrm{~kW}$ \\
& Total & $56 \mathrm{~kW}$ & $70 \mathrm{~kW}$ \\
Weight & & & \\
& MTOW & $572 \mathrm{~kg}$ & $603 \mathrm{~kg}$ \\
& Load weight & $233 \mathrm{~kg}$ & $222 \mathrm{~kg}$ \\
& Useful load weight & $190 \mathrm{~kg}$ & $190 \mathrm{~kg}$ \\
& Fuel weight & $43 \mathrm{~kg}$ & $32 \mathrm{~kg}$ \\
& Battery weight & $10 \mathrm{~kg}$ & $84 \mathrm{~kg}$ \\
& & & \\
Performance & Maximum speed & $177 \mathrm{~km} / \mathrm{h}$ & $182 \mathrm{~km} / \mathrm{h}$ \\
& Cruise speed & $153 \mathrm{~km} / \mathrm{h}$ & $157 \mathrm{~km} / \mathrm{h}$ \\
& Rate of climb & $2.8 \mathrm{~m} / \mathrm{s}$ & $3.0 \mathrm{~m} / \mathrm{s}$ \\
& Take-off roll & $230 \mathrm{~m}$ & $200 \mathrm{~m}$ \\
\hline \hline
\end{tabular}


The performance of the hybrid powered aircraft was also calculated and compared with the prototype aircraft. The maximum speed and cruising speed of the hybrid aircraft are slightly higher than those of the prototype. In addition, higher RoC $(3.0 \mathrm{~m} / \mathrm{s})$ and shorter take-off roll $(200 \mathrm{~m})$ are achieved, due to the higher total propulsion power of the HEPS.

Fig. 11 compares the weight fraction of components for the original combustion system and HEPS. The weight fraction was calculated using the mass of components and MOTW of aircraft. Firstly, the dry mass (excluding fuel and battery) ratio is given in Fig. 11(a). The dry mass of the original propulsion system includes only the engine mass, while the 'dry' components of HEPS comprise the engine, motor, power electronics and clutch. The weight fraction of original propulsion system is over twice larger than one of HEPS 'dry' components. This is partly since the electric motor has higher power density than the combustion engine. Another reason is that lower power requirement means a two-cylinder engine can be used instead of the original four-cylinder engine which was much heavier. Even so, the weight of the two-cylinder engine still occupies the highest portion of the whole dry mass, for the hybrid powertrain.
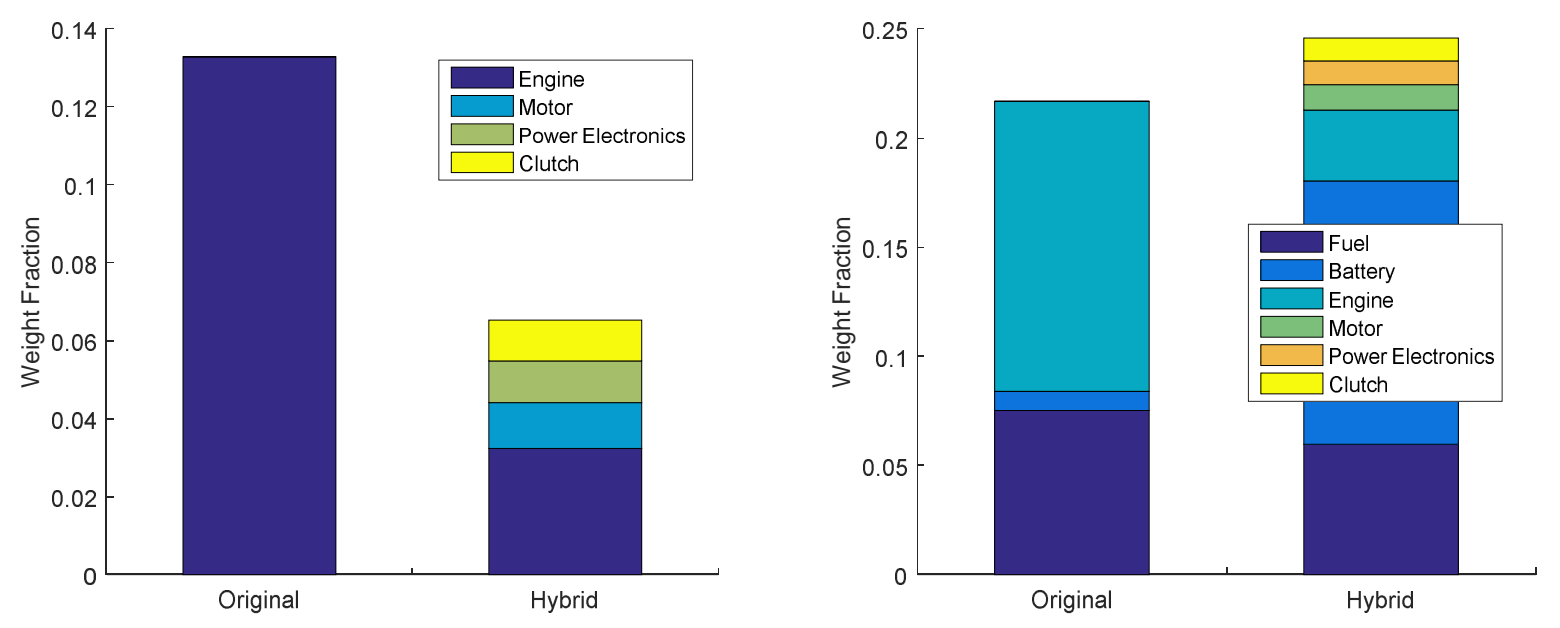

Fig. 11 Comparison of component weight for original and hybrid propulsion system, regarding the dry mass (a) and total mass (b).

Fig. 11(b) provides the weight fraction of the total mass of the original combustion system and HEPS, including both the wet mass (fuel and battery mass) and dry mass. The weight fraction of the total mass of the complete HEPS is higher than for the original propulsion system. Another interesting factor is that for the original combustion system the dry mass takes up the largest ration, while for the HEPS the wet mass consumes most weight. Explicitly, for the original system the engine accounts for over half the total weight, and for the hybrid system it is the battery that accounts for over half the total weight. It can be concluded that the increase of battery energy density can significantly benefit the reduction of hybrid system weight. 


\subsection{Sensitivity Analysis}

This section describes the sensitivity of the optimized results to the length of the emergency time and battery energy density. Note that the test case in Section 4.1 is regarded as the benchmark case and the values of emergency time and battery energy density are $20 \mathrm{~min}$ and $180 \mathrm{Wh} / \mathrm{kg}$, respectively. Different values of emergency time and battery energy density were set for the optimization and the resulting Pareto fronts are given in Fig. 12.

Fig. 12(a) presents the Pareto fronts for $30 \mathrm{~min}$ and 40 min emergency times, compared with the benchmark case of $20 \mathrm{~min}$. It can be concluded that the minimum fuel mass at each flight duration increases with the rise of emergency time. Particularly, the maximum flight duration is only $3 \mathrm{~h}$, if $40 \mathrm{~min}$ emergency time is requested. The requested emergency time can be considered as the desired flight time using only electric propulsion device, also called as electric-only flight time. Fig. 12(a) demonstrates that the prototype aircraft is not suitable to be retrofitted for over 30 min continuously electric-only flying.

As shown in Fig. 12(b), the fuel consumption is reduced if the battery energy density is higher. The figure compares the Pareto fronts of battery energy densities: $180 \mathrm{Wh} / \mathrm{kg}, 280 \mathrm{Wh} / \mathrm{kg}$ and $380 \mathrm{Wh} / \mathrm{kg}$. For an increase in battery energy density of $100 \mathrm{Wh} / \mathrm{kg}$, the fuel consumption decreases by around $10 \%$, at every feasible flight duration.

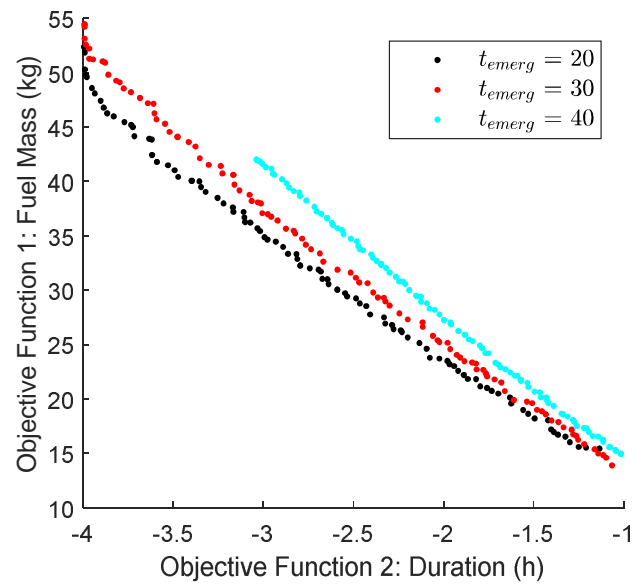

(a)

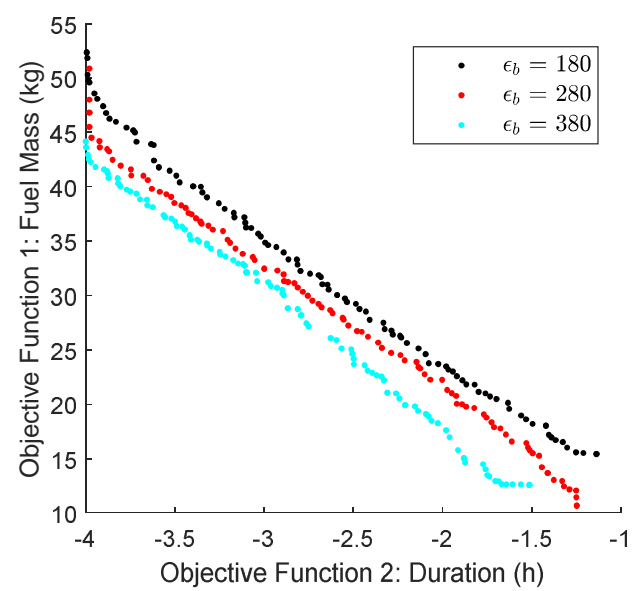

(b)

Fig. 12 Pareto frontiers with different emergency times (a) and batter energy densities (b).

\subsection{Discussion}

From the optimization results and analysis presented above, it is concluded that there are several parameters that significantly affect the fuel consumption of hybrid aircraft.

The first one is the flight duration of the mission cycle, which is set as the contradictory objective function to the fuel usage. It is clear from the Pareto frontier in Fig. 7 that mass of fuel consumed increases with the flight duration. Note that a simple flight mission cycle is used in this study, see Fig. 5, one that contains only the take-off, climbing, 
cruising and landing phases. But the above-mentioned conclusion would be expected to remain true even if complicated mission cycles were considered.

Secondly, the weight of the hybrid propulsion system has a large impact on the fuel economy. As shown in Table 6, the MTOW of the hybrid aircraft is higher than for the prototype. If the global weight of the hybrid aircraft can be reduced, the fuel used to power the flight can be further reduced.

The main contributor to the weight of HEPS is the battery. Fig. 11(b) demonstrates that the battery contributes almost half the total weight of the HEPS. Further, increased battery energy density can reduce battery weight, and thereby effectively reduce the HEPS weight.

Another factor to affect the weight of HEPS is the power density of the selected engine. From Table 6, an additional $74 \mathrm{~kg}$ battery mass is carried by the hybrid aircraft, but the MTOW of the hybrid aircraft is only $31 \mathrm{~kg}$ higher than the prototype. This is partly because a two-cylinder engine is used for the HEPS and this engine has high power density. If a four-cylinder engine is needed, the power density of the engine will be a crucial parameter in determining the mass of the HEPS.

\section{Conclusion}

This paper accomplished the retrofit of a mid-scale aircraft with a HEPS, using the multi-objective optimization. The NSGA algorithm was used for multi-objective optimization and to investigate the best fuel economy of retrofitted hybrid aircraft at different flight durations for the same mission cycle. Compared to the prototype, the hybrid aircraft was able to achieve a reduction in fuel consumption of $17.6 \%$ without any compromise of range or endurance. Additionally, the hybrid aircraft achieved a shorter take-off roll, and higher RoC. A new non-dominated sorting algorithm-BNDS was proposed to improve the computational efficiency of NSGA. This method can reduce lots of unnecessary comparisons and achieve a best time complexity of $O(M N)$.

\section{Acknowledgements}

This work was partly supported by the InnovateUK [grant number 102361]. AIRSTART is a $£ 3.2$ million collaborative Research and Development project developing key technologies to support general aviation, which includes the development of advanced propulsion systems. The authors would like to thank the China Scholarship Council (CSC) for funding Ye Xie to pursue her Ph.D. degree at Cranfield University.

\section{References}

[1] NASA Aeronautics Research Mission Directorate, Strategic Implementation Plan, 2017. https://www.nasa.gov/sites/default/files/atoms/files/sip-2017-03-23-17-high.pdf.

[2] C.C. Chan, The State of the Art of Electric, Hybrid, and Fuel Cell Vehicles, Proc. IEEE. 95 (2007) $704-718$. doi:10.1109/JPROC.2007.892489.

[3] F.G. Harmon, A.A. Frank, J. Chattot, Conceptual Design and Simulation of a Small Hybrid-Electric Unmanned Aerial Vehicle, J. Aircr. 43 (2006) 1490-1498. doi:10.2514/1.15816.

[4] R.M. Hiserote, Analysis of hybrid-electric propulsion system designs for small unmanned aircraft systems, Air Force Institute of Technology, 2010.

[5] R. Glassock, J.Y. Hung, L.F. Gonzalez, R.A. Walker, Design, modelling and measurement of a hybrid powerplant for 
unmanned aerial systems, Aust. J. Mech. Eng. 6 (2008) 69-78. doi:10.1080/14484846.2008.11464559.

[6] J.Y. Hung, L.F. Gonzalez, On parallel hybrid-electric propulsion system for unmanned aerial vehicles, Prog. Aerosp. Sci. 51 (2012) 1-17. doi:10.1016/j.paerosci.2011.12.001.

[7] Jason Paur, Hybrid Power Comes to Aviation, WIRED. (2009). https://www.wired.com/2009/07/hybrid-aviation/ (accessed July 2, 2018).

[8] Embry-Riddle's Eagle Flight Research Center, Propulsion, WIX. (2011). http://embryriddle.wix.com/greenflight3\#!_eagle-flight-research-center/the-eco-eagle/vstc1=propulsion (accessed July 2, 2018).

[9] D. Sigler, Launching on a Leaf Blower and a Hacker, CAFE. (2010). http://cafe.foundation/blog/launching-on-a-leafblower-and-a-hacker/ (accessed July 2, 2018).

[10] Marty K. Bradley, C.K. Droney, Subsonic Ultra Green Aircraft Research: Phase II - Volume II - Hybrid Electric Design Exploration, California, 2015. https://ntrs.nasa.gov/archive/nasa/casi.ntrs.nasa.gov/20150017039.pdf.

[11] L. Leifsson, A. Ko, W.H. Mason, J.A. Schetz, B. Grossman, R.T. Haftka, Multidisciplinary design optimization of blended-wing-body transport aircraft with distributed propulsion, Aerosp. Sci. Technol. 25 (2013) 16-28. doi:10.1016/j.ast.2011.12.004.

[12] R. Kirner, L. Raffaelli, A. Rolt, P. Laskaridis, G. Doulgeris, R. Singh, An assessment of distributed propulsion: Part B Advanced propulsion system architectures for blended wing body aircraft configurations, Aerosp. Sci. Technol. 50 (2016) 212-219. doi:10.1016/j.ast.2015.12.020.

[13] Matthew D. Rippl, Sizing Analysis for Aircraft Utilizing Hybrid-Electric Propulsion Systems, Air Force Institute of Technology, 2011.

[14] J. Van Bogaert, Assessment of Potential Fuel Saving Benefits of Hybrid- Electric Regional Aircraft, Delft University of Technology, 2015.

[15] A.T. Isikveren, Method of Quadrant-Based Algorithmic Nomographs for Hybrid/Electric Aircraft Predesign, J. Aircr. (2017) 1-10. doi:10.2514/1.C034355.

[16] J. Schoemann, M. Hornung, Modeling of Hybrid Electric Propulsion Systems for Small Unmanned Aerial Vehicles, in: 12th AIAA Aviat. Technol. Integr. Oper. Conf. 14th AIAA/ISSMO Multidiscip. Anal. Optim. Conf., American Institute of Aeronautics and Astronautics, Reston, Virigina, 2012: p. 5610. doi:10.2514/6.2012-5610.

[17] C. Pornet, C. Gologan, P.C. Vratny, A. Seitz, O. Schmitz, A.T. Isikveren, M. Hornung, Methodology for Sizing and Performance Assessment of Hybrid Energy Aircraft, J. Aircr. 52 (2015) 1-12. doi:10.2514/1.C032716.

[18] J. Sliwinski, A. Gardi, M. Marino, R. Sabatini, Hybrid-electric propulsion integration in unmanned aircraft, Energy. (2016). doi:10.1016/j.energy.2017.05.183.

[19] R. Glassock, M. Galea, W. Williams, T. Glesk, Hybrid Electric Aircraft Propulsion Case Study for Skydiving Mission, Aerospace. 4 (2017) 45. doi:10.3390/aerospace4030045.

[20] C. Friedrich, P.A. Robertson, Hybrid-Electric Propulsion for Aircraft, J. Aircr. 52 (2015) $176-189$. doi:10.2514/1.C032660.

[21] D.E. Bryson, C.R. Marks, R.M. Miller, M.P. Rumpfkeil, Multidisciplinary design optimization of quiet, hybrid-electric small unmanned aerial systems, J. Aircr. 53 (2016). doi:10.2514/1.C033455.

[22] K. Palt, ERCO Ercoupe 415, (n.d.). http://www.flugzeuginfo.net/acdata_php/acdata_ercoupe_en.php (accessed August 27, 2018).

[23] J.D. Anderson, Aircraft Performance and Design, 1999.

[24] B.H. Carson, Fuel Efficiency of Small Aircraft, J. Aircr. 19 (1982) 473-479. doi:10.2514/3.57417.

[25] MagniX, Permanent Magnet Electric Motors, (n.d.). https://www.magniflux.com/\#Magniflux-Technology (accessed November 20, 2017).

[26] C. Pornet, A.T. Isikveren, Conceptual design of hybrid-electric transport aircraft, Prog. Aerosp. Sci. 79 (2015) $114-135$. doi:10.1016/j.paerosci.2015.09.002.

[27] A. Seshadri, NSGA - II: A multi-objective optimization algorithm, (n.d.). https://uk.mathworks.com/matlabcentral/fileexchange/10429-nsga-ii--a-multi-objective-optimization-algorithm (accessed November 22, 2017).

[28] K. Deb, A. Pratap, S. Agarwal, T. Meyarivan, A fast and elitist multiobjective genetic algorithm: NSGA-II, IEEE Trans. Evol. Comput. 6 (2002) 182-197. doi:10.1109/4235.996017.

[29] X. Zhang, Y. Tian, R. Cheng, Y. Jin, An Efficient Approach to Nondominated Sorting for Evolutionary Multiobjective Optimization, IEEE Trans. Evol. Comput. 19 (2015) 201-213. doi:10.1109/TEVC.2014.2308305.

[30] C. Bao, L. Xu, E.D. Goodman, L. Cao, A novel non-dominated sorting algorithm for evolutionary multi-objective optimization, J. Comput. Sci. 23 (2017) 31-43. doi:10.1016/j.jocs.2017.09.015.

[31] Kokam, KOKAM Li-ion/Polymer Cell, (n.d.). http://kokam.com/data/Kokam_Cell_Brochure_V.4.pdf (accessed November 24, 2017). 
2018-09-24

Sizing of hybrid electric propulsion

system for retrofitting a mid-scale

aircraft using non-dominated sorting

genetic algorithm

Xie, Ye

Xie Y, Savvaris A, Tsourdos A. (2018) Sizing of hybrid electric propulsion system for retrofitting a mid-scale aircraft using non-dominated sorting genetic algorithm. Aerospace Science and

pÿTechnology, Volumes 82 83, November 2018, pp. 323-333

https://doi.org/10.1016/j.ast.2018.09.022

Downloaded from Cranfield Library Services E-Repository 